\title{
Taguchi Based Mechanical Property Optimization Of As Weld Al-65032 Alloy Using Tig Welding
}

\author{
Dara Eshwar ${ }^{1}$, Dr. A.C.S. Kumar ${ }^{2}$ \\ ${ }^{1}$ Professor, Sree vaanmayi institute of Engineering \& Technology, Nalgonda (Dist), Telangana, India \\ ${ }^{2}$ Principal \& Professor, Abhinav Hi-tech Engineering College, Hyderabad, Telangana, India.
}

\begin{abstract}
In recent days, light materials like aluminum alloys are becoming more prominent in real world.In this paper, the parametric design of aluminum alloy (AL 65032) is carried out for the optimum mechanical properties (UTS, $0.2 \%$ proof stress, percentage elongation) using Taguchi techniques. This paper considered only for weld conditions. Hence the parametric design is carried out for TIG welding with as weld condition and with control parameters gas pressure, current, groove angle and preheat. Three levels are considered for the control parameters based on the preliminary tests and analysis is carried out with L-9 orthogonal array.

Keywords: Aluminum alloy, Taguchi technique, TIG, UTS, proof stress, elongation.
\end{abstract}

\section{Introduction}

Recent trend in the automotive world has been transition from conventional materials to light materials like Aluminum alloys[1]. Due to the societal demands for a lower environmental impact through improved fuel efficiency, weight reduction, and load capacity, Aluminum is being more and more widely used in the auto industry because of its light weight. Eventhough, Aluminum in its pure form suffers from poor strength, but when alloyed with other metals, it is an attractive element with wide range of useful properties [1]. Many of the automobile body structures, such as engine cradles, are being manufactured with Aluminum instead of Steel [2].

The welding behavior of Aluminum alloys significantly differ from conventional materials like steel. Improvements in welding technique are desirable as it is one of the methods showing greatest potential for application in industry. However, Gas Metal Arc Welding (GMAW) of Aluminum alloys is more problematic than that of low carbon steels for many reasons [3].Tungsten Inert gas Welding (TIG) and Metal Inert Gas welding (MIG) are the two recommended options for welding aluminum and its alloys [4], TIG and MIG welding processes are multi-objective and multi-factor metal fabrication techniques and several process parameters interact in a complex manner resulting in direct or indirect influence on weld bead geometry, mechanical properties and metallurgical features of the weldment as well as on the weld chemistry [5].

Studying the design parameters one at a time or by trial and error until a first feasible design is found is a common approach to design optimization [6]. However, this leads either to a very long and expensive time span for completing the design or to a premature termination of the design process due to budget or schedule pressures [7].

Taguchi's approach to parameter design provides the design engineer with a systematic and efficient

method for determining near optimum design parameters for performance and cost with an objective of selecting the best combination of control parameters so that the product or process is most robust with respect to noise factors [8]. i.e the aim of parametric design experiment is to identify and design the process parameters to optimize the chosen quality characteristics that are least sensitive to noise factors [9]. The method is suitable for a wide range 01 engineering applications that include processes that manufacture raw materials, components and products for specialized and consumer markets. The various steps to be adopted for the parametric design are [10]:

- Determining the quality characteristics to be optimized

- Identifying the noise factors and test conditions

- Identifying the control parameters and their levels

- Selecting a suitable orthogonal array

- Conducting the experiments as per the orthogonal array

- Analyze the data and determine the optimum levels

- Prediction of performance at determined levels

This paper illustrates the TIG welding of aluminum alloy under different conditions. It proposes a parametric design optimization method for TIG welding. This considers the quality characteristics of mechanical properties such as UTS, $0.2 \%$ proof stress, percentage elongation and impact energy. Noise factors may include variations in environmental operating conditions. 
The rest of this paper is organized as follows. Section II gives the details about the basics of aluminum alloy and its welding properties. Section III gives the complete details of the TIG welding of aluminum alloys. Parametric design optimization of TIG welding is discussed in section IV. Section V gives the analytical results and finally conclusions are provided in section VI.

\section{Tig Welding}

In the fabrication of equipment made from stainless steels such as pipe, automotive exhaust gas system, chemical industrial equipment, etc., Arc welding with shielding gas is often used. Tungsten inert gas (TIG) welding is one such commonly used welding method [11] [12].

TIG welding which uses a non-consumable tungsten electrode and an inert gas for arc shielding, is an extremely important arc welding process. In this process, an electric arc is formed between a tungsten electrode and the base metal. The arc region is protected by an inert gas or mixture of gases. Although this type of welding-is usually done with a single electrode, it may sometimes be done with several electrodes [13]. It is commonly used for welding difficult-to-weld metals such as stainless steel, Aluminum, magnesium, copper and many other nonferrous metals [14-15]. TIG welding process produces high quality weld with easy and precise control of welding parameters. But the disadvantage of this process is shallow weld penetration and lower productivity. So, it can be used for welding the work piece with thickness less than $6 \mathrm{~mm}$ [16].

In TIG welding, shielding gas plays an important role. Shielding gases need to fulfill different requirements: the gases have to be inert with respect to the working materials and at higher temperatures, but some oxygen content should be useful for improving arc stability; high ionization potentials help to reduce the amount of plasma during welding and thus lead to deep penetration but they often lead to arc instability. Besides this the gas must be evenly distributed on the working zone in order to isolate the weld pool and the solidifying material from the environmental atmosphere. Composition of a shielding mixture in arc welding depends mostly on the type of material to be welded.

The selection of the shielding gas should, by all means, take into account chemical, metallurgical processes between the gases and the molten pool that occur during welding [17]. Shielding gas type and shielded environment due to gas distribution into the heat source-material interaction zone are probably the most important parameters in a welding process and they can deeply affect the quality and reliability of the welded joints [18], Density of the shielding gas has an important influence on the efficiency of shielding the arc and the weld pool against the ambient atmosphere. The values indicating relative density of the shielding gas with regard to air are of primary importance. Argon and carbon dioxide are the gases having by far the highest density and therefore, form an efficient gas shielding around the arc.

However, the densities of Hydrogen and Helium are 10-20 times less than that of Argon and thus, are prone to turbulent flow at the exit from the blowpipe nozzle due to thermal buoyancy [19],

TIG welding is a traditional technology for Aluminum alloy welding [21]. However, some problems may occur, such as hot cracking in fusion zone due to segregation of alloying elements during solidification, ascast coarse micro structure [22], which result in the obvious decrease of mechanical properties of the joints.

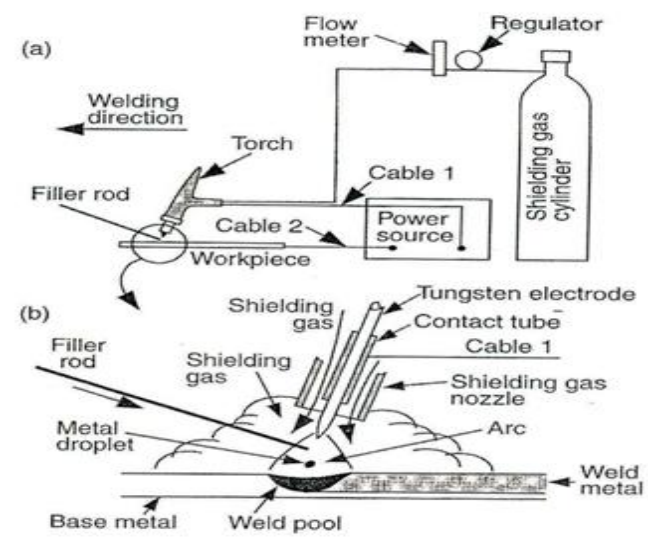

Fig 1 Tungsten Inert Gas Welding a)Schematic diagram b)at the weld zone [20]

The welding structure can turn out to be the limiting factor for Aluminum alloy in aerospace applications

\section{A. Development Of Tig Welding Equipment}

After the discovery of the electric arc in 1800 by Humphrey Davy, arc welding technique emerged and developed significantly. C. L. Coffin had the idea of welding in an inert gas atmosphere in 1890, but even in the early 1900s, welding non-ferrous materials like Aluminum and magnesium remained difficult, as these metals reacted rapidly with the air, resulting in porous and dross-filled welds. Processes using flux covered electrodes 
do not satisfactorily protect the weld area from contamination. To solve this problem, bottled inert gases were used in the beginning of the 1930s. A few years later, a direct current, gas-shielded welding process emerged in the aircraft industry for welding magnesium.

This process was perfected in 1941, and popularly known as heliarc or tungsten inert gas welding, because it utilized a tungsten electrode and helium as a shielding gas. Initially, the electrode overheated quickly, and in spite of tungsten's high melting temperature, particles of tungsten were transferred to the weld. To address this problem, the polarity of the electrode was changed from positive to negative, but this made it unsuitable for welding many non-ferrous materials. Finally, the development of alternating current units made it possible to stabilize the arc and produce high quality Aluminum and magnesium welds.

Developments continued during the following decades. Lindc Air Products developed water-cooled torches that helped in preventing overheating when welding with high currents. Additionally, during the 1950s, as the process continued to gain popularity, some users turned to carbon dioxide as an alternative to the more expensive welding atmospheres consisting of argon and helium [23], However, this proved unacceptable for welding Aluminum and magnesium because it reduced weld quality, and as a result, it is rarely used with GTAW now a days.

In 1953, a new process based on GTAW was developed, called plasma arc welding. It affords greater control and improves weld quality by using a nozzle to focus the electric arc, but is largely limited to automated systems, whereas GTAW remains primarily a manual, hand-held method. Development in the GTAW process has continued subsequently which resulted in a number of variations. Among them, the most popular processes are the pulsed-current, manual programmed, hot-wire, and increased penetration GTAW methods.

\section{B. Operation Of Tig Welding}

Manual gas tungsten arc welding is often considered the most difficult among all the welding processes commonly used in industry. Because the welder must maintain a short are length, great care and skill are required to prevent contact between the electrode and the work piece [24]. Similar to torch welding, GTAW normally requires two hands, since most of the applications require that the welder manually feed a filler metal into the weld area with one hand while manipulating the welding torch in the other. However, some welds combining thin materials (known as autogenous or fusion welds) can be accomplished without filler metal; most notably edge, corner, and butt joints.

To strike the welding arc, a high frequency generator (similar to a Tesla coil) provides a spark; this spark is a conductive path for the welding current through the shielding gas and allows the arc to be initiated while the electrode and the work piece are separated, typically about $1.5-3 \mathrm{~mm}(0.06-0.12 \mathrm{inch})$ apart. This high voltage, high frequency burst may lead to damage of some vehicle electrical systems and electronics, because induced voltages on vehicle wiring can cause small conductive sparks in the vehicle wiring or within semiconductor packaging. Vehicle with $12 \mathrm{~V}$ power may conduct across these ionized paths, driven by the highcurrent $12 \mathrm{~V}$ vehicle battery. These currents may be sufficiently destructive to disable the vehicle; thus giving a warning to disconnect the vehicle battery power from both $+12 \mathrm{~V}$ and ground before using welding equipment on vehicles.

An alternate way to initiate the arc is the "scratch start". Scratching the electrode against the work with the power ON mode also serves to strike an arc, in the same way as SMAW ("stick") arc welding. However, scratch starting may cause contamination of the weld and electrode. Some GTAW equipment with a mode called "touch start" or "lift arc" is capable of reducing the voltage on the electrode to only a few volts, with a current limit of one or two amps (well below the limit that causes metal to transfer and contamination of the weld or electrode). When the GTAW equipment detects that the electrode has left the surface and a spark is present, it immediately (within microseconds) increases power, converting the spark to a full arc.

Once the arc is struck, the welder moves the torch in a small circle to create a weld pool, the size of which depends on the size of the electrode and-the amount of current. While maintaining a constant separation between the electrode and the work piece, the operator then moves the torch back slightly and tilts it backward about 10-15 degrees from vertical. Filler metal is added manually to the front end of the weld pool as and when it is needed;

Welders often develop a technique of rapidly alternating between moving the torch forward (to advance the weld pool) and adding filler metal. The filler rod is withdrawn from the weld pool each time the electrode advances, but it is never removed from the gas shield to prevent oxidation of its surface and contamination of the weld. Filler rods composed of metals with low melting temperature, such as Aluminum, require that the operator maintain some distance from the arc while staying inside the gas shield. If held too close to the arc, the filler rod can melt before it makes contact with the weld puddle. As the weld nears completion, the arc current is often gradually reduced to allow the weld crater to solidify and prevent the formation of crater cracks at the end of the weld. 


\section{Taguchi Design Optimization}

The complete design optimization is performed based on Taguchi method. The complete details about the Taguchi method are described in this section. Taguchi developed a method for designing experiments to investigate how different parameters affect the mean and variance of a process performance characteristic that defines how well the process is functioning. The experimental design proposed by Taguchi involves using orthogonal arrays to organize the parameters affecting the process and the levels at which they vary.

The general steps involved in the Taguchi Method are as follows:

- Define the process objective, or more specifically, a target value for a performance measure of the process. This may be a flow rate, temperature, etc. The target of a process may also be a minimum or maximum; for example, the goal may be to maximize the output flow rate. The deviation in the performance characteristic from the target value is used to define the loss function for the process.

- Determine the design parameters affecting the process. Parameters are variables within the process that affect the performance measure such as temperatures, pressures, etc. that can be easily controlled. The number of levels that the parameters should be varied at must be specified.

- Create orthogonal arrays for the parameter design indicating the number of and conditions for each experiment. The selection of orthogonal arrays is based on the number of parameters and the levels of variation for each parameter, and will be explained below.

- Conduct the experiments as per the array to collect data on the effect on the performance measure.

- Complete data analysis to determine the effect of the different parameters on the performance measure.

Taguchi method [25] has been used to investigate optimization of the pulsed TIG welding process parameters for increasing the mechanical properties. Using Taguchi method permits evaluation of the effects of individual parameters independent of other parameters and interactions on the identified quality characteristics, i.e. ultimate tensile strength, yield strength, hardness, etc. Nowadays, Taguchi method has become a practical tool for improving the quality of the output without increasing the cost of experimentation by reducing the number of experiments. The effect of many different parameters on the performance characteristic in a condensed set of experiments can be examined by using the orthogonal array. Experimental design proposed by Taguchi. Once the parameters affecting a process that can be controlled have been determined, the levels at which these parameters should be varied must be determined. The S/N ratio developed by Taguchi chooses control levels that best cope with noise. The $\mathrm{S} / \mathrm{N}$ ratio takes both the mean and the variability into account. Similarly ANOVA analyzes the variance. It considers both within group variance and also between group variance.

$\sigma_{\text {Total }}^{2}=\sigma_{\text {Between }}^{2}+\sigma_{\text {Within }}^{2} \ldots \ldots \ldots \ldots \ldots$........ (1)

Between-groups variance is the variation in the responses between the different groups and is assumed to be due to an independent variable. Within-groups variance is the random variation in responding that cannot be attributed to the independent variable and is due to uncontrollable differences among subjects.

Similarly an another parameter called F-Ratio is also proposed by taguchi .Divide the between group variance by the within group variance, which is called the F-Ratio

$\mathrm{F}=\underline{\sigma}^{2}$ Between ................. (2)

The confidence interval (CI) of predicted mean of optimum quality characteristic on confirmation test is estimated using below equation

$\mathrm{CI}=\sqrt{\mathrm{F}(\propto, \mathrm{v} 1, \mathrm{v} 2) \mathrm{vw} \frac{1}{\mathrm{~N}_{\mathrm{eff}}}+\frac{1}{\mathrm{R}}}$

Where $\mathrm{N}_{\text {eff }}=\mathrm{N} / 1+\mathrm{T}_{\mathrm{DOF}} \mathrm{F}(\alpha, \mathrm{V} 1, \mathrm{~V} 2)$ is the standard value of $\mathrm{F}$ for 100(1- a) confidence level, $\mathrm{V} 1$ is the degrees of freedom of the factor and V2 is the degrees of freedom of the error, $\mathrm{R}$ is the number of replications of the confirmation experiment, $\mathrm{N}$ is the total number of experiments. TDOF is degrees of freedom of mean.

\section{Optimization Results}

Based on the above procedure of Taguchi, the experiments are conducted for 9 runs for three sample and the respective results (UTS, proof stress and percentage elongation) is observed. The obtained results are represented below. For each run the quality characteristics (UTS, proof stress and percentage elongation) are found from the stress-strain curves obtained. The signal to noise $(\mathrm{S} / \mathrm{N})$ ratio for each quality characteristic is calculated, the significant parameters are identified and the optimum input parameter for each quality characteristic is predicted from the $\mathrm{S} / \mathrm{N}$ values and the mean response. $\mathrm{S} / \mathrm{N}$ ratio is computed for the UTS values obtained for the three samples of 9 runs and are presented table 1 . 
Table.1 UTS values and S/N value of as weld samples with TIG welding

\begin{tabular}{|c|c|c|c|c|c|c|c|c|}
\hline Run & Pressure & Current & Angle & $\begin{array}{c}\text { Pre- } \\
\text { heating }\end{array}$ & \multicolumn{3}{|c|}{ UTS } & S/N \\
\hline 1 & 1 & 1 & 1 & 1 & 187.35 & 185.03 & 186.12 & 45.3977 \\
\hline 2 & 1 & 2 & 2 & 2 & 181.37 & 183.79 & 181.26 & 45.2076 \\
\hline 3 & 1 & 3 & 3 & 3 & 177.45 & 178.01 & 175.74 & 44.9623 \\
\hline 4 & 2 & 1 & 2 & 3 & 186.17 & 184.68 & 184.59 & 45.3501 \\
\hline 5 & 2 & 2 & 3 & 1 & 181.92 & 180.53 & 179.27 & 45.1326 \\
\hline 6 & 2 & 3 & 1 & 2 & 182.58 & 184.37 & 183.74 & 45.2755 \\
\hline 7 & 3 & 1 & 3 & 2 & 186.29 & 185.53 & 189.36 & 45.4386 \\
\hline 8 & 3 & 2 & 1 & 3 & 181.02 & 178.24 & 178.14 & 45.0628 \\
\hline 9 & 3 & 3 & 2 & 1 & 179.58 & 181.81 & 180.45 & 45.1347 \\
\hline
\end{tabular}

The average $\mathrm{S} / \mathrm{N}$ values for each parameter at three levels are calculated and presented in table 2 . The range (A) for each parameter is computed. Higher value of A indicates higher the relative effect of parameter on the quality characteristic. TheAverage $\mathrm{S} / \mathrm{N}$ ratio of process parameters for the UTS of as weld samples with TIG welding is shown in below figure 2.

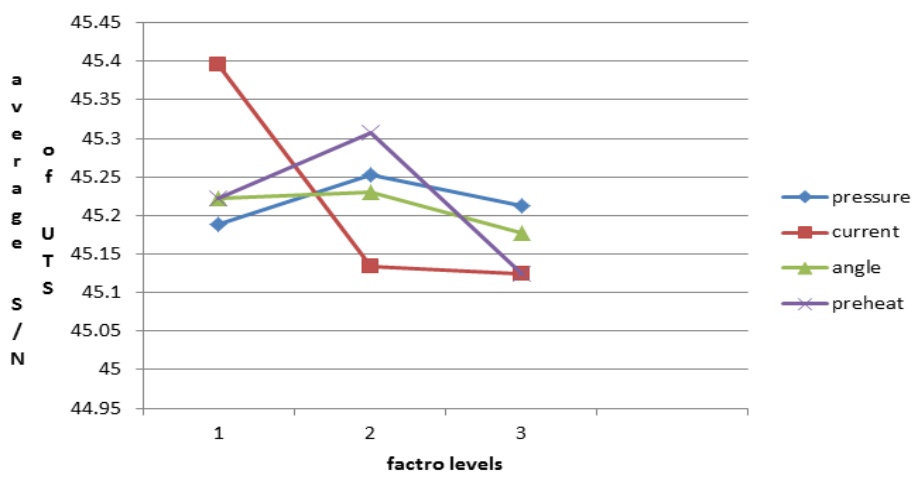

Fig.2.Effect of Process parameters on average S/N ratio for UTS as weld samples with TIG welding From the above figure it is clear that the maximum UTS is at pressure-2, current- 1 and preheat- 2 .

Similarly the analysis is carried out for $0.2 \%$ proof stress and presented in table 2 and figure 3 . It is evident that the most influencing parameters that affect proof stress are also current followed by preheating. Table 2S/N values for Proof Stress of as weld samples with TIG welding

\begin{tabular}{|c|c|c|c|c|c|c|c|c|}
\hline Run & Pressure & Current & Angle & $\begin{array}{l}\text { Pre- } \\
\text { heating }\end{array}$ & \multicolumn{2}{|c|}{$0.2 \%$} & Proof Stress & S/N \\
\hline 1 & 1 & 1 & 1 & 1 & 98.14 & 96.37 & 96.79 & 39.7436 \\
\hline 2 & 1 & 2 & 2 & 2 & 95.53 & 96.59 & 94.98 & 39.6176 \\
\hline 3 & 1 & 3 & 3 & 3 & 100.34 & 96.47 & 97.68 & 39.8355 \\
\hline 4 & 2 & 1 & 2 & 3 & 109.21 & 111.36 & 109.89 & 40.8391 \\
\hline 5 & 2 & 2 & 3 & 1 & 104.33 & 106.19 & 105.23 & 40.4438 \\
\hline 6 & 2 & 3 & 1 & 2 & 103.64 & 102.25 & 100.32 & 40.1756 \\
\hline 7 & 3 & 1 & 3 & 2 & 101.87 & 104.24 & 103.45 & 40.2713 \\
\hline 8 & 3 & 2 & 1 & 3 & 110.45 & 109.51 & 107.62 & 40.7624 \\
\hline 9 & 3 & 3 & 2 & 1 & 94.34 & 96.23 & 94.53 & 39.5565 \\
\hline
\end{tabular}

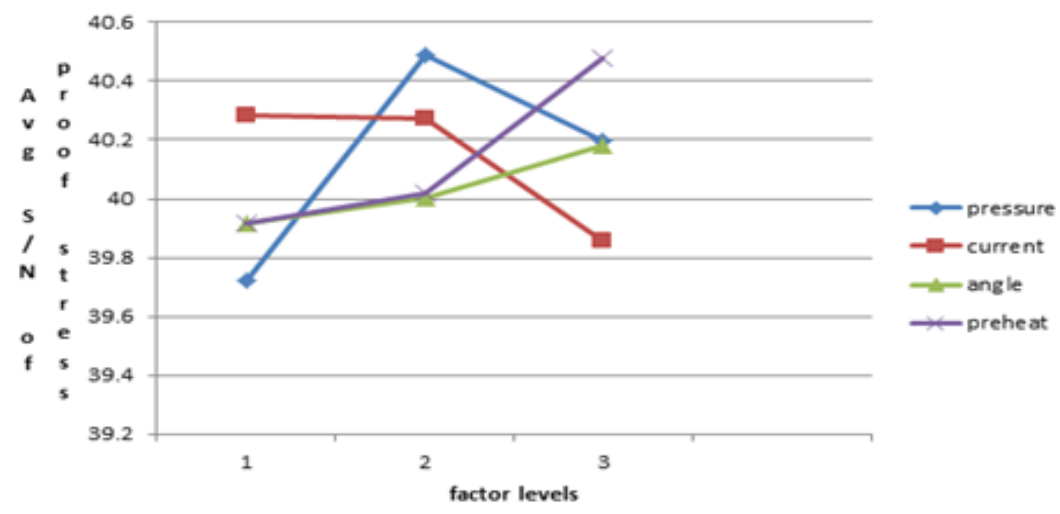

Fig.3. effect of process parameters on average $\mathrm{S} / \mathrm{N}$ ratio for proof stress as weld samples with TIG welding. $\mathrm{S} / \mathrm{N}$ values for percentage elongation and average $\mathrm{S} / \mathrm{N}$ ratio of the process parameters for the percentage elongation are presented in table 3 and figure 4 respectively 
Table3 S/N values for percentage elongation of as weld samples with TIG welding.

\begin{tabular}{|c|c|c|c|c|c|c|c|c|}
\hline Run & Pressure & Current & Angle & Preheating & Percen & age Elo & ngation & $\mathrm{S} / \mathrm{N}$ \\
\hline 1 & 1 & 1 & 1 & 1 & 13.53 & 12.66 & 14.71 & 22.6431 \\
\hline 2 & 1 & 2 & 2 & 2 & 14.82 & 13.12 & 13.78 & 22.832 \\
\hline 3 & 1 & 3 & 3 & 3 & 10.16 & 11.01 & 9.23 & 20.0473 \\
\hline 4 & 2 & 1 & 2 & 3 & 12.62 & 11.97 & 12.42 & 21.8175 \\
\hline 5 & 2 & 2 & 3 & 1 & 13.97 & 13.37 & 14.23 & 22.8242 \\
\hline 6 & 2 & 3 & 1 & 2 & 14.28 & 14.86 & 13.95 & 23.1363 \\
\hline 7 & 3 & 1 & 3 & 2 & 15.14 & 15.89 & 14.97 & 23.7041 \\
\hline 8 & 3 & 2 & 1 & 3 & 16.23 & 17.34 & 15.72 & 24.2911 \\
\hline 9 & 3 & 3 & 2 & 1 & 15.34 & 14.87 & 15.13 & 23.5851 \\
\hline
\end{tabular}

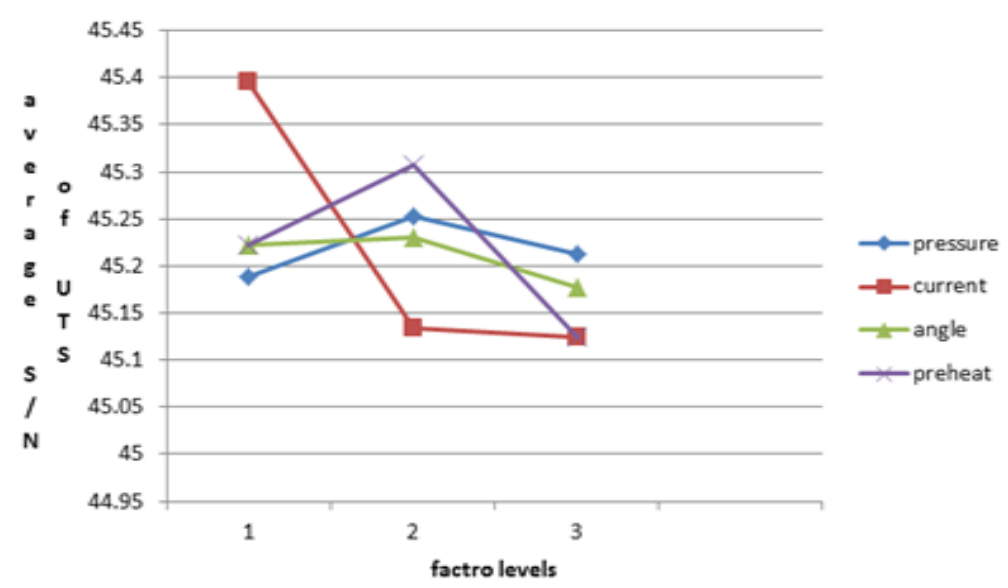

Fig.4. effect of process parameters on average $\mathrm{S} / \mathrm{N}$ ratio for percentage elongation as weld samples with TIG welding.

ANOVA (Analysis of variance) is also carried out to find out the relative significance of each parameter on the mechanical properties. ANOVA is a statistically based objective decision making tool for detecting any differences in average performance of the groups of items tested taking the variation into account rather than using pure judgment. The ANOVA table for UTS is presented in table 4.

Table.4. ANOVA table for UTS of as weld samples with TIG welding

\begin{tabular}{|l|l|l|l|l|l|}
\hline source & SS & DOF & MS & F & P \\
\hline Pressure & 18.94 & 2 & 9.254 & 0.24624 & 0.4521 \\
\hline Current & 2652.362 & 2 & 1320.664 & 32.0313 & 68.0235 \\
\hline Angle & 156.201 & 2 & 78.0025 & 1.89127 & 4.0185 \\
\hline Preheat & 325.742 & 2 & 162.3206 & 3.9523 & 8.6325 \\
\hline
\end{tabular}

ANOVA table for proof stress is presented in table 5. From table 5, it is evident that the preheat, pressure (at 99\% confidence level) and current (at 95\% confidence level) are the significant parameters in affecting the proof stress with a contribution of $31.5 \%, 21 \%$ and $17.9 \%$ respectively.

Table 5.ANOVA table for $0.2 \%$ Proof Stress of as weld samples with TIG welding

\begin{tabular}{|l|l|l|l|l|l|}
\hline source & SS & DOF & MS & F & P \\
\hline Pressure & 2435.234 & 2 & 1217.112 & 6.5 & 21.0478 \\
\hline Current & 2.72 .04 & 2 & 1036.256 & 5.50248 & 17.9387 \\
\hline Angle & 24.589 & 2 & 13.99250 & 0.07546 & 0.25843 \\
\hline Preheat & 3654.234 & 2 & 1822.845 & 9.75249 & 31.7555 \\
\hline
\end{tabular}

Table.6. ANOVA table for percentage elongation of as weld samples with TIG welding

\begin{tabular}{|l|l|l|l|l|l|}
\hline source & SS & DOF & MS & F & P \\
\hline Pressure & 762.2131 & 2 & 381.6512 & 46.5572 & 58.9741 \\
\hline Current & 25.6840 & 2 & 12.3092 & 1.27489 & 1.96354 \\
\hline Angle & 234.6198 & 2 & 117.1891 & 14.3763 & 18.1234 \\
\hline Preheat & 123.2341 & 2 & 61.6175 & 7.75230 & 9.58450 \\
\hline
\end{tabular}


ANOVA test for percentage elongation (table 4.6) reveals that pressure is the most significant parameter that effects the percentage elongation at $99 \%$ confidence level with a contribution of $58.9 \%$. This is also in line with the $\mathrm{S} / \mathrm{N}$ analysis.

\section{Conclusions}

In this paper, the most significant parameters that affect the mechanical properties of TIG weldments of Al 65032 alloy are investigated without heat treatment using $\mathrm{S} / \mathrm{N}$ analysis and mean response analysis and parametric design is carried out for better mechanical properties. Further, ANOVA is carried out to ensure the results obtained from the above analyses are optimal.

\section{References}

[1]. Praveen. P, Yarrlagadda. P.K.D.V: Meeting Challenges in welding of Al-alloys through pulse gas metal arc welding, 'Journal of Material Processing Technology', Vol 164-165, (2005) pp.1106-1112

[2]. Mathers.G: The welding of aluminum and its alloys, Wood Head publishing Ltd, England, 2002 pp.4-5.

[3]. Jang, K.C, Lee D.G, kuk. J.M, Kim I.S: Welding and environmental test condition effect in weldability and strength of Aluminum alloy, 'Journal of Material Processing Technioiogy', Vol 164-165, (2005), pp.1038-1045

[4]. John L; Campbell: Welding Aluminum Different, but not Difficult, 'Fabricator', May-June 1999, pp. 1-4

[5]. UgurEsme; MelihBayramoglu; YugutKazancoglu; SuedaOzgun: Optimization of Weld Bead Geometry In TIG Welding Process Using Grey Relation Analysis and Taguchi. Method, 'Materials and technology1 vol. 43, no.3, 2009, pp.143-149.

[6]. Phadke, S. M: Quality Engineering Using Robust Design, Prentice Hall, Englewood Cliffs, N.J., 1989.

[7]. ResitUnal; Edwin, B; Dean: Taguchi Approach To Design Optimization For Quality And Cost: An Overview, 'Annual Conference of the International Society of Parametric Analysts' 1991, pp. 1-10

[8]. Kackar; Raghu: Off-Line Quality Control, Parameter Design, and the Taguchi Method, 'Journal of Quality Technology' 1985, vol. 17, no.4, pp.176-188.

[9]. [9].Prabir Kumar Chaulia; Reeta Das: Process Parameter optimization for Fly Ash Brick by Taguchi Method, Materials Research' 2008, vol.11, no.2, pp.159-164

[10]. DalgobindMahto;AnjaniKumar:Optimization of Process Parameters in Vertical CNC Mill Machines Using Taguchi's Design of Experiments,'ARISER'2008, vol.4 no.2, pp.61-75.

[11]. AhmetDurgutlu: Experimental Investigations of the effect of Hydrogen in Argon as a shielding gas on TIG Welding of austenitic stainless steel, 'Materials \& Design' Vol.25, 2004,pp.19-23.

[12]. Lothongkum.G, Viyanit.E, BhanduBhanyaonj.P: Study on the effects of pulsed TIG welding parameters on delta ferrite content shape factor and bead quality in orbital welding of AISI-316 L stainless steel plate, 'Journal of Material Processing Technology', 2001, Vol. 110 (2), pp.233-238.

[13]. Minnnick. W.H: Gas Tungsten Arc Welding Hand Book, The good heart-willcox company inc., 1996.

[14]. Hicken .O.K. 'Gas Tungsten Arc Welding' Vol.6, ASM hand book, 1993, pp.190-193.

[15]. Althouse. A.D, Turnquist .C.H, Bowditch. W.A, Bowditch.K.A: Gas Tungsten Arc Welding, Modern Welding, The good heartwillcox company inc., 1992. Pp.327-328.

[16]. Liquing-ming, Wang, Xin-Hong, ZouZeng-Da, WU jun: Effect of activating flux on Arc shape and arc voltage in tungsten inert gas welding, 'Transactions of nonferrous metals society of China', Vol. 17, 2007, pp.486- 490.

[17]. Tusek.J, Suban.M: Experimental Research of the effect of Hydrogen in Argon as a shielding gas in Arc welding of high alloy stainless steel. 'International Journal of Hydrogen Energy1, 2000, Vol.25 (4), pp.369-376

[18]. Gampana G, Ascari A, Fortunato A, Tani G; Hybrid Laser MIG welding of aluminum alloys: the influence of shielding gases, 'Applied surface science', Vol. 255, 2009, pp.5588-5590.

[19]. Suban.M, Tusek.J: 'Dependance of metal rate in MIG-MAG welding on type of shied gas used, 'Journal of Material Processing Technology' , 2001, Vol. 119, pp,185-192.

[20]. Minnick, William H: Gas tungsten arc welding handbook. Tinley Park, Illinois; Goodheart-Willcox Company', 1996.

[21]. Juanzhao, FengXeong Jiang, HaigenJian, Kang wen, Long Jiang, Xiaobio Chen: Comparative investigation of tungsten inert gas (TIG) and friction stir welding characteristics of Al-Mg-Sc alloy plates, 'Materials \& Design', Vol 31, 2010 , pp.306- 311.

[22]. Sato. Y.S., Akrom.P, Kokawaa.H, Nelson.T.E, Steel. R.J: Effect of Micro structure on properties of fricion stir welded Inconel alloy 600, 'Material Science Engineering A', 2008, vol.477, pp.250-258.

[23]. ASM International: Trends in welding research. Materials Park, 'Ohio, ASM International', 2003.

[24]. Incoln Electric: The procedure handbook of arc welding, 'Cleveland, Lincoln Electric', 1994.

[25]. Huang.C ,Kou.S: Liquation Mechanisms in multi Component Aluminum alloy during Welding, 'welding Research Journal', Otober'2002, pp.211-222. 